\title{
The Longitudinal Aging Study Amsterdam: cohort update 2019 and additional data collections
}

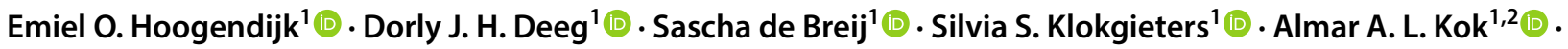

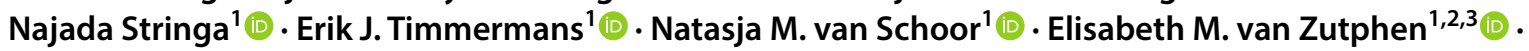 \\ Marleen van der Horst ${ }^{1} \cdot$ Jan Poppelaars ${ }^{1,4}$. Priyanta Malhoe ${ }^{1} \cdot$ Martijn Huisman $^{1,4}(\mathbb{D}$
}

Received: 9 July 2019 / Accepted: 20 July 2019 / Published online: 25 July 2019

(c) The Author(s) 2019

\begin{abstract}
The Longitudinal Aging Study Amsterdam (LASA) is a prospective cohort study of older adults in the Netherlands, initially based on a nationally representative sample of people aged 55-84 years. The study has been ongoing since 1992, and focuses on the determinants, trajectories and consequences of physical, cognitive, emotional and social functioning. Strengths of the LASA study include its multidisciplinary character, the availability of over 25 years of follow-up, and the cohort-sequential design that allows investigations of longitudinal changes, cohort differences and time trends in functioning. The findings from LASA have been reported in over 600 publications so far (see www.lasa-vu.nl). This article provides an update of the design of the LASA study and its methods, on the basis of recent developments. We describe additional data collections, such as additional nine-monthly measurements in-between the regular three-yearly waves that have been conducted among the oldest old during 2016-2019, and the inclusion of a cohort of older Turkish and Moroccan migrants.
\end{abstract}

Keywords Longitudinal studies · Cohort studies · Netherlands · Epidemiology · Aging · Genotyping data · Older migrants · Study design

\section{Introduction}

The Longitudinal Aging Study Amsterdam (LASA) is a prospective cohort study among older adults in the Netherlands. The study started in 1992, initiated by the Dutch Ministry of Welfare, Health and Culture (currently Ministry of Health, Welfare and Sports), and is still ongoing. The primary objective of LASA was to study the determinants, trajectories and

Emiel O. Hoogendijk

e.hoogendijk@amsterdamumc.nl

1 Department of Epidemiology and Biostatistics, Amsterdam Public Health Research Institute, Amsterdam UMC -

Location VU University Medical Center, Amsterdam, The Netherlands

2 Department of Psychiatry, Amsterdam Public Health Research Institute, Amsterdam UMC - Location VU University Medical Center, Amsterdam, The Netherlands

3 GGZ InGeest Specialized Mental Health Care, Amsterdam, The Netherlands

4 Department of Sociology, Faculty of Social Sciences, Vrije Universiteit, Amsterdam, The Netherlands consequences of (changes in) functioning in four domains: physical, cognitive, emotional and social functioning [1, 2]. LASA is one of the few longitudinal studies of older adults in the Netherlands [3, 4], and worldwide among the few studies covering a broad range of functional domains. The main strengths of the study include its multidisciplinary character, the availability of over 25 years of follow-up, and the inclusion of refresher cohorts of young older adults at 10 and 20 years after the start of the study. This structure provides unique opportunities to investigate longitudinal trajectories, cohort differences and time trends in functioning of older adults $[5,6]$.

In this paper, we briefly describe the design of LASA and provide an update of the methods. In particular, this paper describes the additional data collections that have not been described in detail previously, such as data collected in telephone interviews, additional nine-monthly measurements among the oldest old, genetic data, environmental data, and the inclusion of a migrant cohort. 


\section{The design of LASA}

The LASA cohort was initially based on a representative sample of older adults aged 55-84 years (born between 1908 and 1937) from three regions in the Netherlands. These three regions (areas in and around the cities of Zwolle, Oss and Amsterdam) were selected to obtain an optimal representation of the Dutch older population. The regions cover the predominantly protestant northeast, the largely catholic south and the more secularized western part of the Netherlands, and include both urbanized and rural areas. The initial LASA sample consists of people who first participated in the NESTOR study on Living Arrangements and Social Networks of older adults (LSN) [7]. The sample for the LSN study was randomly selected from municipality registers in 1992, with an oversampling of the oldest old and men. This oversampling was done to ensure that there would be reasonable numbers of oldest old and very old men, even after several years of followup. The initial sample of the LSN study consisted of 3805 persons, which corresponds to a response rate (defined as the number of complete and partial interviews, divided by the total number of eligible persons in the sample plus a fraction of those persons who were in the sample but of whom eligibility could not be determined) of $60 \%$. The cooperation rate (defined as the number of completed interviews divided by the total number of contacted eligible persons) was $62 \%$.
On average, 11 months after the LSN interview (wave A), respondents were invited to participate in the first wave of LASA (wave $\mathrm{B}, \mathrm{n}=3107$ ). The response rate was $85 \%$ and the cooperation rate was $89 \%$. Since the 1992 LSN measurement wave, there have been nine LASA measurement waves to date (Figs. 1, 2). At the eighth measurement wave (wave I), approximately 23 years after the start of the study, a total of 500 respondents from the original cohort were still participating.

Two refresher cohorts were added to the original sample in 2002-2003 and 2012-2013, exactly 10 and 20 years after the start of the LASA study. Figure 2 and Table 1 show the sample sizes for the three cohorts across all measurement waves and by interview type. The second cohort (included in 2002-2003) consisted of 1002 men and women born between 1938 and 1947 (cooperation rate $=62 \%$ ), and the third cohort (included in 2012-2013) consisted of 1023 men and women born between 1948 and 1957 (cooperation rate $=63 \%$ ). In follow-up measurements after the baseline measurement, respondents from these new cohorts were merged with those from the original cohort. At the end of 2019, the data collection of the most recent measurement wave (wave J), consisting of the remaining respondents from all three cohorts, will be completed.

The LASA study is conducted in line with the Declaration of Helsinki and received approval by the medical ethics committee of the VU University Medical Center (IRB numbers: 92/138, 2002/141, 2012/361, and 2016.301).

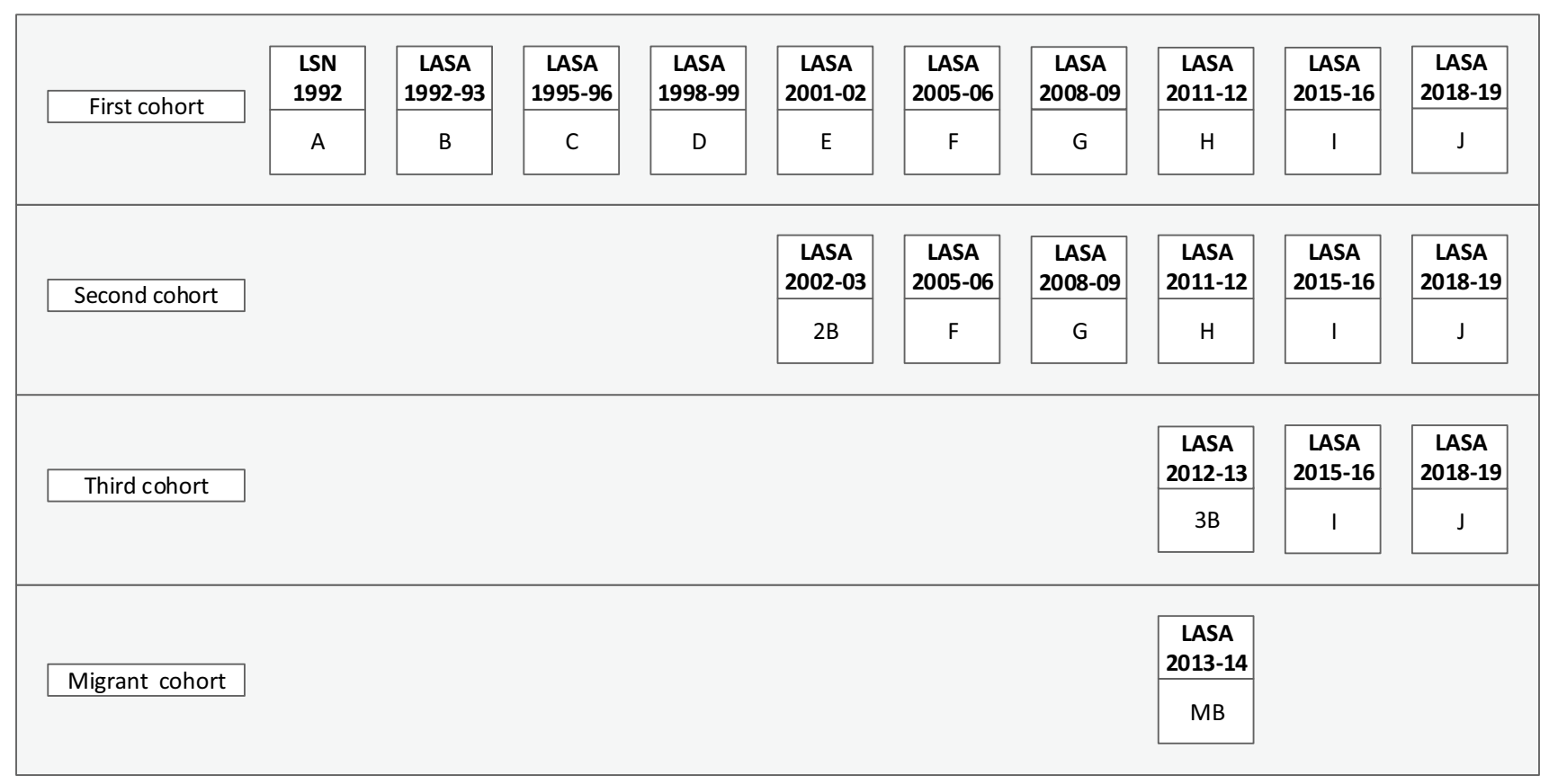

Fig. 1 Overview of LASA cohorts and measurement waves 


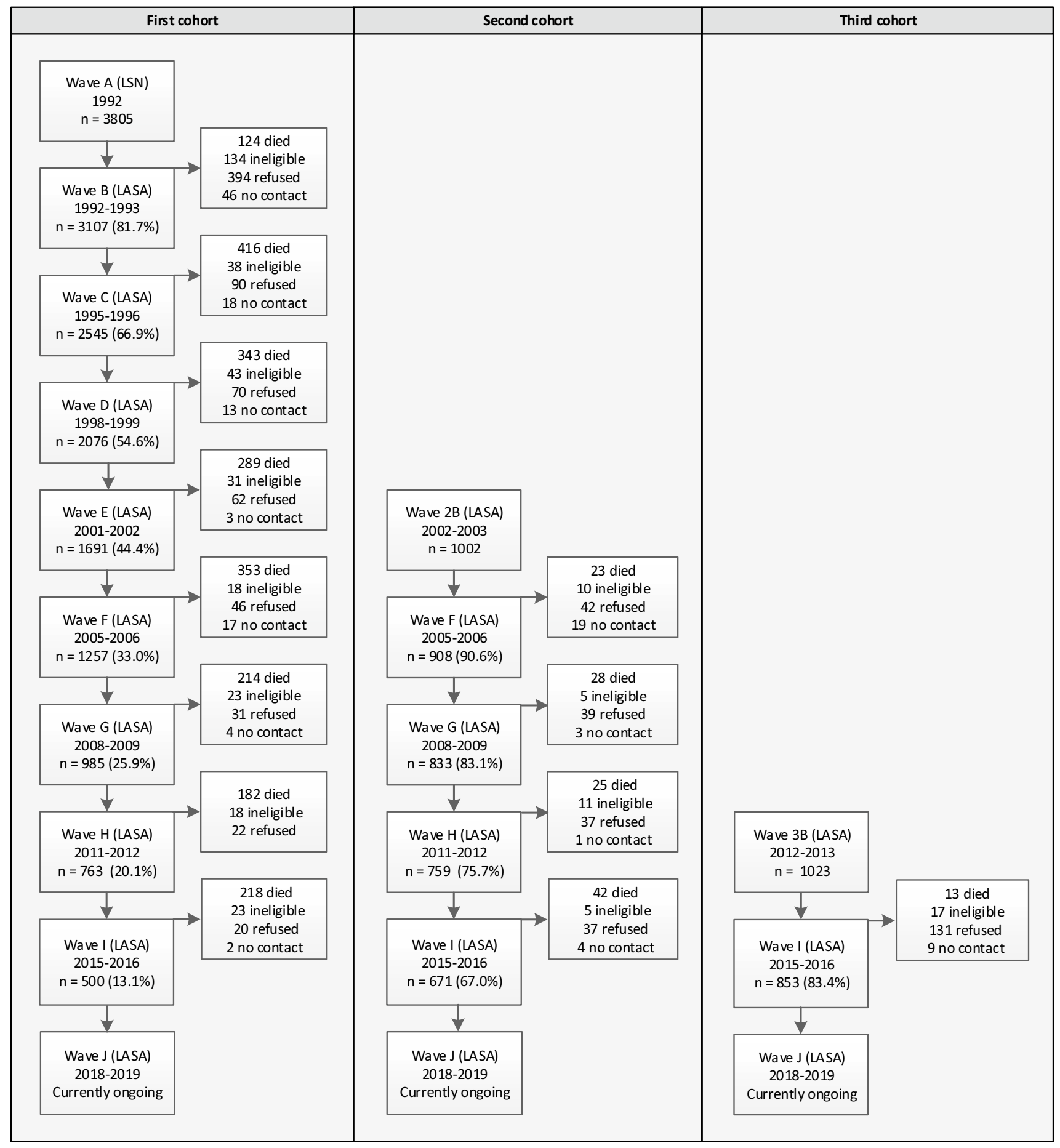

Fig. 2 LASA study flowchart

\section{Data collection}

\section{Face-to-face interviews}

Respondents are visited every 3 to 4 years at home by trained interviewers who collect the data. All interviews (if respondents agree) are audio-recorded for quality checks. Measurements are performed for each of the four domains of functioning: physical, cognitive, emotional and social functioning. The data collection includes both questionnaires and clinical tests. An overview of the main predictors and outcome measures in LASA has been published 
Table 1 LASA interview type by measurement wave

\begin{tabular}{|c|c|c|c|c|c|c|c|}
\hline \multirow[t]{3}{*}{ Wave } & \multirow[t]{3}{*}{ Year } & \multirow[t]{3}{*}{ Cohort $^{\mathrm{a}}$} & \multirow[t]{3}{*}{ Age range } & \multirow[t]{3}{*}{$\mathrm{n}$} & \multicolumn{3}{|l|}{$\mathrm{n}$ by interview type } \\
\hline & & & & & \multirow{2}{*}{$\begin{array}{l}\text { Face-to-face } \\
\text { Main interview } \\
\text { (medical interview) }\end{array}$} & \multicolumn{2}{|l|}{ Telephone } \\
\hline & & & & & & Respondent & Proxy \\
\hline B & 1992-1993 & Cohort 1 & $55-84$ & 3107 & 3107 (2671) & - & - \\
\hline $\mathrm{C}$ & 1995-1996 & Cohort 1 & $57-88$ & 2545 & $2302(1509)^{\mathrm{b}}$ & 164 & 79 \\
\hline $\mathrm{D}$ & 1998-1999 & Cohort 1 & $60-91$ & 2076 & $1874(1382)^{\mathrm{c}}$ & 127 & 75 \\
\hline E & 2001-2002 & Cohort 1 & $63-94$ & 1691 & 1474 (1307) & 122 & 95 \\
\hline $2 \mathrm{~B}$ & $2002-2003$ & Cohort 2 & $55-64$ & 1002 & $1002(919)$ & - & - \\
\hline $\mathrm{F}$ & 2005-2006 & Cohort 1,2 & $57-98$ & 2165 & 1908 (1805) & 140 & 117 \\
\hline G & 2008-2009 & Cohort 1,2 & $60-100$ & 1818 & 1601 (1494) & 117 & 100 \\
\hline $\mathrm{H}$ & 2011-2012 & Cohort 1,2 & 63-104 & 1522 & 1308 (1212) & 99 & 115 \\
\hline 3B & 2012-2013 & Cohort 3 & $55-64$ & 1023 & $1023(889)$ & - & - \\
\hline MB & 2013-2014 & Migrant cohort & $55-64$ & 478 & $478(344)$ & - & - \\
\hline I & 2015-2016 & Cohort $1,2,3$ & $57-102$ & 2024 & 1770 (1642) & 148 & 106 \\
\hline
\end{tabular}

a'Birth years Cohort 1: 1908-1937, Cohort 2: 1938-1947, Cohort 3: 1948-1957, Migrant cohort: 19481957

b In 1995-1996, only people born before 1931 were asked to participate in the medical interview

${ }^{c}$ In 1998-1999, only people born before 1931 plus a control group of remaining birth years were asked to participate in the medical interview before [2]. Detailed descriptions of the measurements can be found on the LASA website (www.lasa-vu.nl). The data collection consists of three elements: a main interview, a self-administered questionnaire and a medical interview. The main interview takes, on average, almost $2 \mathrm{~h}$ to complete. An abbreviated interview may be offered to the respondent when a full interview is too burdensome to complete. At the end of the main interview, respondents are asked to fill out a self-administered questionnaire, which is left at the respondent's home in print, or can be accessed online (as of 2015). Respondents are asked to hand in this questionnaire during the medical interview, to return it by postal mail, or to complete the questionnaire online. Respondents are also invited to participate in a subsequent medical interview. After consent, a separate visit is scheduled, in which additional questions are asked and clinical measurements are performed. This medical interview takes on average $1 \mathrm{~h}$ and a half to complete. Respondents who score highly on the symptom checklists of depression or anxiety are invited for an additional diagnostic psychiatric interview. At specific measurement waves (waves B, C, 2B, G and 3B) blood samples were obtained from respondents who participated in the medical interview [2].

\section{Telephone data}

Since LASA measurement wave C (1995-1996), a telephone interview is offered to those respondents who refused to participate in a full or an abbreviated face-to-face interview. The telephone interview takes approximately $15 \mathrm{~min}$ and includes a selection of key indicators of functioning (see Table 2). While this interview mode was initially intended to obtain information from proxy respondents, it turned out that quite a few respondents were willing to answer the telephone questions themselves even though they could not participate in the face-to-face interview. Across all measurement waves up to 2015-2016 (wave I), the majority of telephone interviews was in fact conducted with respondents: $4.4 \%$ of all interviews were done by telephone with respondents, versus $3.3 \%$ by telephone with proxies.

Across all measurement waves, respondents with telephone data were older than respondents with face-to-face data, less often lived with a partner and more often lived in a care institution. Net of age, there were no differences in level of education. Respondents with telephone data were also less healthy in terms of number of chronic diseases, functional limitations and self-rated health than those with face-to-face data. Besides being too frail, one reason for respondents to refuse a face-to-face interview, is that they may be too busy. In 2015-2016 (wave I), respondents aged 74 years or younger were asked about paid work and number of hours of work. It turned out that telephone respondents indeed had paid work relatively often (38.6\% vs. $32.1 \%$ among face-toface respondents) and that those who worked also worked relatively long hours $(32.8 \mathrm{~h}$ vs. $29.3 \mathrm{~h}$ among face-to-face respondents). Both differences were, however, not statistically significant. In order to better reflect the variation in the population, it is recommended that telephone data are used in addition to face-to-face data, whenever the research question allows it. This helps to minimize selection bias. 
Table 2 Measures in telephone interview

\begin{tabular}{|c|c|c|c|c|c|c|c|c|c|}
\hline \multirow{2}{*}{$\frac{\text { Measure }}{\text { Demographic data (housing, partner status) }}$} & \multirow{2}{*}{$\begin{array}{l}\text { Availability } \\
\text { Respondent + proxy }\end{array}$} & \multicolumn{8}{|c|}{ Measurement waves } \\
\hline & & $\mathrm{C}$ & $\mathrm{D}$ & $\mathrm{E}$ & $\mathrm{F}$ & G & $\mathrm{H}$ & I & $\mathrm{J}$ \\
\hline Chronic diseases & Respondent + proxy & $\mathrm{C}$ & $\mathrm{D}$ & $\mathrm{E}$ & $\mathrm{F}$ & G & $\mathrm{H}$ & I & $\mathrm{J}$ \\
\hline Functional limitations & Respondent + proxy & $\mathrm{C}$ & $\mathrm{D}$ & E & $\mathrm{F}$ & $\mathrm{G}$ & $\mathrm{H}$ & I & $\mathrm{J}$ \\
\hline Senses (vision, hearing) & Respondent + proxy & $\mathrm{C}$ & $\mathrm{D}$ & E & $\mathrm{F}$ & G & $\mathrm{H}$ & I & $\mathrm{J}$ \\
\hline Fractures/falls ${ }^{\mathrm{a}}$ & Respondent + proxy & $\mathrm{C}$ & $\mathrm{D}$ & $\mathrm{E}$ & $\mathrm{F}$ & G & $\mathrm{H}$ & I & $\mathrm{J}$ \\
\hline Weight change & Respondent & & & & & & & I & $\mathrm{J}$ \\
\hline \multirow[t]{2}{*}{ Depressive symptoms (CES-D) } & Respondent & $\mathrm{C}$ & $\mathrm{D}$ & E & $\mathrm{F}$ & G & $\mathrm{H}$ & I & $\mathrm{J}$ \\
\hline & Proxy & $\mathrm{C}$ & $\mathrm{D}$ & E & & & & & \\
\hline Cognitive decline (IQCODE) & Proxy & $\mathrm{C}$ & $\mathrm{D}$ & E & $\mathrm{F}$ & G & $\mathrm{H}$ & I & $\mathrm{J}$ \\
\hline General cognitive functioning (MMSE, short version) & Respondent & & $\mathrm{D}$ & E & $\mathrm{F}$ & G & $\mathrm{H}$ & I & $\mathrm{J}$ \\
\hline Salience of religion & Respondent + proxy & $\mathrm{C}$ & & & & & & & \\
\hline End of life (advance directives) & Respondent & & $\mathrm{D}$ & & & & & & \\
\hline Use of care & Respondent + proxy & $\mathrm{C}$ & $\mathrm{D}$ & $\mathrm{E}$ & $\mathrm{F}$ & G & $\mathrm{H}$ & I & $\mathrm{J}$ \\
\hline Needs assessment (facilities, social services, care) & Respondent + proxy & & & & & G & $\mathrm{H}$ & I & $\mathrm{J}$ \\
\hline Loneliness (De Jong Gierveld loneliness scale, short version) & Respondent & & & & & & $\mathrm{H}$ & I & $\mathrm{J}$ \\
\hline Employment and retirement & Respondent & & & & & & & I & $\mathrm{J}$ \\
\hline
\end{tabular}

$C E S-D$ Center for Epidemiologic Studies Depression scale, IQCODE Informant Questionnaire of Cognitive Decline in The Elderly, MMSE Mini Mental State Examination

${ }^{a}$ Information on falls is only available at wave C, D and J

\section{Attrition and representativeness}

Attrition of respondents over time is a key concern for longitudinal studies, which may affect the representativeness of the sample [1]. The main reason for drop-out in LASA is mortality $[1,2,8]$. If mortality in the LASA study differs from mortality in the general population, this could be a threat for the representativeness of the study, as it could lead to an increasingly selective sample. Therefore, analyses were performed to compare mortality among LASA respondents with mortality in the Dutch general population. Data on mortality in the general population by sex, year and age group were obtained from Statistics Netherlands [9]. The results show that mortality was slightly higher in the general population than in the LASA sample, but for most groups differences did not exceed 1 percent point (Table 3). Thus, it can be concluded that mortality in the LASA study is not substantially different from mortality rates in the Dutch general older population.

A further indication of the representativeness of the LASA cohorts is obtained by comparing the frequency of work participation between LASA and the general population as assessed by Statistics Netherlands, for the age group 55-64 years. We performed this comparison for the baseline wave of the second (wave 2B, 2002-2003) and third cohort (wave 3B, 2012-2013), for men and women and for three levels of education. Work participation was defined as having paid work for $1 \mathrm{~h}$ or more. The difference between frequencies in LASA and the general population was 2.6 percent points on average, thus showing good correspondence. Across subgroups, the differences ranged from 0.2 to 6.9 percent points. The larger deviations were observed for women and the lower educated, which may be attributed to the greater precariousness of work in these groups, so that their work participation is more likely to fluctuate over time.

\section{Methods update}

\section{Additional nine-monthly measurements among the oldest old}

The oldest old are in a stage of life in which changes in functioning can occur more rapidly and more catastrophically than earlier in life. For example, cognitive decline markedly accelerates during the last years of life [10]. Therefore, it is important to accurately monitor trajectories of functioning and changes in functioning in this age group. At the same time, there have been recent changes in policy in the Netherlands that may particularly affect the oldest old. As of 2015, the Social Support Act (WMO) directs municipalities to provide support for people with functional limitations, including instrumental support at home, home care and social care, which was previously regulated by the national government. This may lead to variations in care provision between different municipalities. In addition, the Long-term Care Act for residential care (WLZ), and the Care Insurance Act for personal and nursing home care at home (ZVW) 
Table 3 Mortality among LASA respondents compared to the Dutch general population

\begin{tabular}{lll}
\hline & \multicolumn{2}{l}{$\begin{array}{l}\text { Weighted sum of difference (LASA } \\
\text { minus Dutch population) })^{\mathrm{a}, \mathrm{b}}\end{array}$} \\
\cline { 2 - 3 } & Men & Women \\
\hline Total & -0.73 & -0.51 \\
By year & & \\
1994 & -0.53 & -0.54 \\
1997 & -0.75 & -0.50 \\
2000 & -1.00 & -0.81 \\
2004 & -0.72 & -0.57 \\
2007 & -0.38 & -0.09 \\
2010 & -0.94 & -0.45 \\
2014 & -0.89 & -0.63 \\
By age & & -0.16 \\
$60-64$ years & -0.37 & -0.06 \\
$65-69$ years & -0.40 & -0.45 \\
$70-74$ years & -0.37 & -0.97 \\
$75-79$ years & -1.03 & -1.09 \\
$80-85$ years & -1.74 & \\
\hline
\end{tabular}

${ }^{a}$ Expressed in percent point difference. All differences were summed, and weights were applied for the number of LASA-respondents in each group

${ }^{b}$ We estimated 1-year mortality in LASA by dividing the percentage that died between subsequent measurement waves by three, since the interviews were held with 3-year intervals. Exceptions were the interval between wave E/2B (2001-2003) and wave F (2005-2006), which was on average 3.7 years, and the interval between wave H/3B (20112013) and wave I (2015-2016), which was on average 3.6 years. For each year $(\mathrm{t})$, the percentage that died in each age group (X) between two successive waves in LASA was calculated as follows: number of deaths in age group $X$ (at the time of death) between the two waves/ number of deaths + number of survivors in age group X (at January 1 in year $t$, where $t$ is the mid-year between two waves)

were implemented. In these acts, thresholds for access to care were raised, making it more difficult to be eligible for residential care, which can lead to an increased reliance on informal care and privately paid care. The absolute increase in the number of oldest old in the community, the rapid changes in functioning among the oldest old and the recent policy changes were the main reasons for conducting an ancillary study among the oldest LASA respondents with increased density of measurements.

Three additional nine-monthly measurements were performed between the regular LASA measurements in 2015-2016 (wave I) and 2018-2019 (wave J). Thus, together with these regular measurement waves, data from five consecutive nine-monthly measurements will become available for studying changes and trajectories of the four domains of functioning. All persons aged 75 years and over (born before 1941) were invited to participate in this ancillary study $(n=686)$. In total, 601 persons agreed to participate
(87.6\%). At the first additional measurement (wave $\mathrm{I}-\mathrm{v} 1$ ), $442(73.5 \%)$ participated in a face-to-face home interview and $159(26.5 \%)$ participated in a telephone interview (61 with respondent and 98 with proxy). The topics included in the interview, as well as the response rates for each additional nine-monthly measurement, are presented in Table 4. Respondents who had a face-to-face interview were asked to fill out a one-week calendar to study changes in pain, use of pain medication, mood, sleep, social contacts and appetite on a daily basis. Respondents were asked to return the calendar by postal mail.

\section{Genetic data}

Blood samples from respondents participating in the LASA medical interview in 1995-1996 (wave C), 2002-2003 (wave 2B), 2008-2009 (wave G) and 2012-2013 (wave 3B) were used to obtain genetic data. In the first and second cohort, DNA was isolated from buffy coats in wave $\mathrm{C}$ and wave 2B and from full blood samples in wave G. For respondents from whom both full blood samples and buffy coats were available, the full blood samples were used to extract DNA. In the third cohort, full blood samples drawn at baseline (wave 3B) were used for DNA isolation. In all samples, DNA was extracted using standard procedures.

In 2016-2017 genotyping array data were generated for respondents who had blood samples available. First, a batch of around 600 samples was genotyped using Axiom-NL array [11] (Affymetrix Inc., Santa Clara, CA, USA) at the Avera Institute for Human Genetics, Sioux Falls, SD, USA. Then, another 1880 samples from the first, second and third cohort were genotyped using Infinium Global Screening Array-24-v.1.0 (GSA) (Illumina Inc., San Diego, CA, USA) at the Genetic Laboratory, Department of Internal Medicine, Erasmus MC, Rotterdam, the Netherlands. Due to technical differences, quality control and imputation were performed separately for each array. For both arrays, quality control was performed using Ricopili (RICOPILI: Rapid Imputation for COnsortias PIpeLIne) [12], an established tool developed by the Psychiatric Genomics Consortium [13, 14]. Samples with sex mismatch, duplicate samples, excess heterozygosity and call rate $<0.98$ were removed after quality control. Single nucleotide polymorphism (SNPs) with call rate $<0.98$ and minor allele frequency $<0.01$ were also excluded. Ancestry related principal components for each array were calculated. Samples of non-European ancestry were identified and later removed using the 1000 Genome data as reference. Then, 10 principal components were re-calculated for each array for European ancestry respondents. The data was further checked for relatedness between respondents. 
Table 4 Ancillary study: additional nine-monthly measurements among the oldest old (born before 1941)

\begin{tabular}{|c|c|c|c|}
\hline Response & Wave I-v1 & Wave $\mathrm{I}-\mathrm{v} 2$ & Wave $I-v 3$ \\
\hline Date range interviews & July 2016-July 2017 & April 2017-April 2018 & $\begin{array}{l}\text { January 2018-Janu- } \\
\text { ary } 2019\end{array}$ \\
\hline Invited, $\mathrm{n}$ & 686 & 601 & 550 \\
\hline Participated, n (\%) & $601(87.6)$ & $550(91.5)$ & $507(92.2)$ \\
\hline Age, mean (SD) & $83.0(5.4)$ & $83.4(5.2)$ & $83.8(4.9)$ \\
\hline \multicolumn{4}{|l|}{ Data available } \\
\hline Face-to-face interview, $\mathrm{n}$ & 442 & 410 & 364 \\
\hline Calendar data, $\mathrm{n}^{\mathrm{a}}$ & 387 & 368 & 325 \\
\hline Telephone interview Respondent, $\mathrm{n}$ & 61 & 55 & 59 \\
\hline Telephone interview Proxy, n & 98 & 85 & 84 \\
\hline \multicolumn{4}{|l|}{ Measures } \\
\hline Face-to-face interview & \multicolumn{3}{|c|}{$\begin{array}{l}\text { Demographic data, gait speed, grip strength, chronic diseases, self-rated health, functional limitations, } \\
\text { homecare/informal care, care needs, healthcare use, depressive symptoms (CES-D, short version), } \\
\text { falls and fractures, memory complaints, cognitive functioning (MMSE, coding task), loneliness (De } \\
\text { Jong Gierveld loneliness scale, short version), weight measurement, self-reported weight change, } \\
\text { physical activity, pain, end of life care and preferences, and partner health }\end{array}$} \\
\hline Calendar data & \multicolumn{3}{|c|}{$\begin{array}{l}\text { One-week calendar, with questions on pain ( } 1-10 \text {; severe pain-no pain), use of pain medication (yes/ } \\
\text { no), mood (1-10; very bad-very good), sleep (1-10; very bad-very good), social contact (number of } \\
\text { people), and appetite (1-5; very bad-very good) on a daily basis }\end{array}$} \\
\hline Telephone interview & \multicolumn{3}{|c|}{$\begin{array}{l}\text { Demographic data, chronic diseases, self-rated health, functional limitations, homecare/informal care, } \\
\text { care needs, healthcare use, depressive symptoms (CES-D, short version), falls and fractures, memory } \\
\text { complaints, cognitive functioning (MMSE, short version), loneliness (De Jong Gierveld loneliness } \\
\text { scale, short version), self-reported weight change, physical activity, pain, end of life care and prefer- } \\
\text { ences, and partner health }\end{array}$} \\
\hline
\end{tabular}

${ }^{\text {a }}$ Calendar data is only available for those participating in the face-to-face interview

Overall, genotyping array data are available for European-ancestry, non-related respondents $(n=2279)$; from cohort $1(\mathrm{n}=1081$, of which $\mathrm{n}=590$ genotyped with Axiom-NL and $n=491$ genotyped with GSA), from cohort $2(n=631)$ and from cohort $3(n=567)$. After quality control, both arrays were separately used to impute the data using as reference the Haplotype Reference Consortium panel version 1.1 [15]. Imputation for autosomal chromosomes (chr1-22) was done using Minimac 3 and was facilitated by the Michigan Imputation Server [16].

Genotyping data available in LASA can be used in candidate gene studies, to build polygenic risk scores for complex traits and in genome-wide association studies (GWAS). In combination with the rich pool of physical, cognitive, emotional and social phenotypes in LASA, genotyping array data are a valuable resource for geneenvironment interaction studies. LASA has been included in GWAS meta-analyses from the CHARGE and GEFOS consortia recently as well as other collaborations [17-19].

Exome chip data and a number of SNPs in candidate genes are available for a subsample of respondents in the first cohort $(n=1193)$ (see for example [20]). Furthermore, genotyping of Apolipoprotein E gene is also available for a subset of respondents in the second cohort $(\mathrm{n}=753)$. An overview of the exome chip data and candidate SNPs has been previously published [2].

\section{Chronic disease and composite algorithms}

In LASA, various sources of data on chronic disease are available, including self-reported chronic diseases, medication use in the two weeks before the interview and diagnoses from general practitioner (GP) records. Since none of these data sources are the gold standard to measure disease status, chronic disease ascertainment algorithms were developed. In these algorithms, data from different sources are combined [21]. Algorithms were constructed for seven cardiovascular diseases (CVD) (angina pectoris, myocardial infarction, coronary artery disease, congestive heart failure, peripheral arterial disease, cardiac arrhythmia and cerebrovascular accident), diabetes mellitus and osteoarthritis [22-24]. Using these algorithms, respondents were categorized as definitely, possibly or not having a disease, contradictory data, or as missing when there are no data available. An illustrative example of diabetes mellitus disease status according to the chronic disease algorithm and other sources is shown in Table 5. An advantage of the algorithm is that it reflects the degree of uncertainty related to the use of medication, diagnoses reported by GPs and self-report of disease 
Table 5 Prevalence of diabetes mellitus at LASA wave C: Comparison between the revised diabetes mellitus algorithm and other data sources

\begin{tabular}{lllllc}
\hline Source & $\begin{array}{l}\text { Definite } \\
\mathrm{n}(\%)\end{array}$ & $\begin{array}{l}\text { No } \\
\mathrm{n}(\%)\end{array}$ & $\begin{array}{l}\text { Possible } \\
\mathrm{n}(\%)\end{array}$ & $\begin{array}{l}\text { Contradictory } \\
\mathrm{n}(\%)\end{array}$ & $\begin{array}{l}\text { Missing } \\
\mathrm{n}(\%)\end{array}$ \\
\hline Self-reported $^{\mathrm{a}}$ & $199(7.8)$ & $2334(91.7)$ & - & - & $12(0.5)$ \\
General practitioner $^{\mathrm{b}}$ & $192(7.5)$ & $1794(70.3)$ & $37(1.5)^{\mathrm{c}}$ & - & $522(20.5)$ \\
Medication $^{\mathrm{b}}$ & $89(3.7)$ & $1420(55.8)$ & - & - & $1036(40.7)$ \\
Algorithm $^{1}$ & $180(7.1)$ & $2301(90.4)$ & $14(0.6)$ & $49(1.9)$ & $1(0)$ \\
\hline
\end{tabular}

${ }^{a}$ Derived from face-to-face interview with respondent or telephone interview with respondent or proxy

${ }^{\mathrm{b}}$ Based on ATC code A10 (drugs used in diabetes)

${ }^{c}$ Year of diagnosis was missing, therefore the diagnosis cannot be linked to a specific LASA wave or symptoms as measures for disease status. Moreover, combining data from various sources in an algorithm reduces the number of cases with missing data.

In 2018, the previously developed algorithms for CVD and diabetes mellitus were revised for several reasons. First, the algorithms could only be constructed for the B, C and $\mathrm{D}$ waves as some items on self-report of disease differed in content in later waves. Second, the use of certain medications is very disease specific, yet the diagnosis of the GP carried more weight in the former algorithms. This resulted in counter-intuitive diagnoses, for example a respondent who uses insulin was classified as 'possibly' having diabetes mellitus. For angina pectoris, cardiac arrhythmia and diabetes mellitus, the use of disease specific medication was given precedence over the other variables in the revised algorithms. Third, we have included data from the telephone interviews in the revised algorithms in order to reduce the number of cases categorized as missing. Chronic disease ascertainment algorithms are available for LASA waves B, $\mathrm{C}, \mathrm{D}, \mathrm{E}, 2 \mathrm{~B}, \mathrm{~F}$ and $\mathrm{G}$ and will be developed for more recent waves as well.

Furthermore, algorithms for composite indices were constructed for the metabolic syndrome, allostatic load and frailty [25-29]. Metabolic syndrome and allostatic load algorithms are currently available for wave $\mathrm{C}$ only, but the metabolic syndrome algorithm can also be constructed for waves $\mathrm{B}$ and $2 \mathrm{~B}$ (using antidiabetic medication as marker for fasting glucose) and for wave G. Algorithms for two widely used frailty constructs, the frailty phenotype (Fried criteria) and the frailty index (deficit accumulation approach) have been established from wave $\mathrm{C}$ onwards, combining selfreported and performance data [30-33].

Lastly, an algorithm for Persistent Cognitive Decline (PCD) was developed to identify participants with probable dementia [34]. For wave $\mathrm{C}$ to $\mathrm{H}$, this was determined on the basis of: (a) decline in global cognition, measured by the MMSE (>2 SD decline since previous wave); (b) the Informant Questionnaire on Cognitive Decline in the Elderly (IQCODE; score > 27); (c) interviewer-reported reasons for loss to follow-up (if reason was 'dementia'); (d) data from GP registries, indicating that a diagnosis of dementia was reported by the GP and/or specialist; and (e) psychogeriatric nursing home admittance and the presence of dementia as a cause of death. Based on this algorithm, 3-year incidence of PCD in LASA was estimated to be about 3\% [34]. More details on the disease and composite algorithms have been published on the LASA website (www.lasa-vu.nl).

\section{Environmental data}

The LASA study has been included in two cohort consortia that focus on the relationship between the environment and health outcomes: the Geoscience and Health Cohort Consortium (GECCO; www.gecco.nl) [35] and the MINDMAP project (www.mindmap-cities.eu) [36]. In GECCO, various large-scale and ongoing cohort studies in the Netherlands have been enriched with a variety of existing, objectively measured, environmental data that were collected from different sources [35]. The MINDMAP project aims to identify the opportunities and challenges posed by urban environmental characteristics for the promotion and management of mental well-being and cognitive function of older adults [36]. This consortium brings together cohort studies across cities in Europe, Canada and the United States of America, and links these cohorts with databases of area-level environmental exposures and social and urban policy indicators. The environmental data collected for the GECCO consortium and MINDMAP project can be linked to individual LASA respondent data using their 4-digit postal codes or, where possible, 6-digit postal codes as the identifier.

The main environmental data that are currently available in LASA are shown in Table 6 and include: urbanization grade (i.e., number of residents $/ \mathrm{km}^{2}$ ), population demographics (e.g., age- and sex-distribution, marital status and proportions of immigrants and ethnic minority groups), household characteristics (e.g., average household size), educational level (e.g., proportions of individuals who attained high, intermediate or low education), income (e.g., average income and proportion of income recipients), socioeconomic status (e.g., socioeconomic status score), social security (e.g., proportion of social security beneficiaries), air pollution (e.g., concentrations of air pollutants), noise (e.g., 
Table 6 Availability of environmental data in LASA

\begin{tabular}{|c|c|c|c|}
\hline Environmental data & Spatial scale & Currently available for the years & Original data source \\
\hline Urbanization grade & Neighborhood & $1995,1997,1999,2001$, from 2003 to 2014 & Statistics Netherlands \\
\hline Population demographics & $\begin{array}{l}\text { PC4 } \\
\text { Neighborhood }\end{array}$ & $\begin{array}{l}\text { From } 1998 \text { to } 2014 \\
1995,1997,1999,2001,2003-2014\end{array}$ & Statistics Netherlands \\
\hline Household characteristics & $\begin{array}{l}\text { PC4 } \\
\text { Neighborhood }\end{array}$ & $\begin{array}{l}\text { From } 1998 \text { to } 2014 \\
1995,1997,1999,2001,2003-2014\end{array}$ & Statistics Netherlands \\
\hline Educational level & PC4 & 2014 & Statistics Netherlands \\
\hline Income & Neighborhood & $1995,1997,1999,2001,2003,2005$, from 2009 to 2014 & Statistics Netherlands \\
\hline Socio-economic status score & PC4 & 1998, 2002, 2006, 2010, 2014 & $\begin{array}{l}\text { The Netherlands Institute } \\
\text { for Social Research }\end{array}$ \\
\hline Social security & Neighborhood & From 2003 to 2006 , from 2008 to 2014 & Statistics Netherlands \\
\hline Air pollution & $\begin{array}{l}\text { Addresses } \\
\text { PC6 } \\
\text { PC4 }\end{array}$ & $\begin{array}{l}2009 \\
2009 \\
2009\end{array}$ & $\begin{array}{l}\text { Institute for Risk Assess- } \\
\text { ment Sciences }\end{array}$ \\
\hline Noise & $\begin{array}{l}\text { Addresses } \\
\text { PC6 } \\
\text { PC4 }\end{array}$ & $\begin{array}{l}\text { 2000, 2004, 2005, 2007, 2008, 2010, } 2011 \\
\text { 2000, 2004, 2005, 2007, 2008, 2010, } 2011 \\
2000,2004,2005,2007,2008,2010,2011\end{array}$ & $\begin{array}{l}\text { Netherlands Environmental } \\
\text { Assessment Agency }\end{array}$ \\
\hline Crime & Neighborhood & From 2010 to 2015 & Statistics Netherlands \\
\hline Availability of facilities & Neighborhood & From 2008 to 2014 & Statistics Netherlands \\
\hline $\begin{array}{l}\text { Physical environment (green space, } \\
\text { water) }\end{array}$ & Neighborhood & 2006 & Statistics Netherlands \\
\hline Daily average weather parameters & Nationwide & From 2010 to 2012 & $\begin{array}{l}\text { The Royal Netherlands } \\
\text { Meteorological Institute }\end{array}$ \\
\hline
\end{tabular}

This is an overview of the main environmental data currently available in LASA. More data may become available in the future. For a complete overview, see www.gecco.nl

PC4 4-digit postal code area, PC6 6-digit postal code area

road-traffic, rail-traffic and air-traffic noise), crime rates (e.g., number of criminal offenses per 1000 residents), availability of facilities (e.g., in terms of density of/proximity to specific health care facilities and socio-cultural facilities), physical environmental characteristics (e.g., green space and water) and daily average weather parameters (e.g., daily average temperature and humidity). Several of these variables have been used in recent LASA studies [35, 37-41].

\section{Migrant cohort}

In 2013-2014, a sample of older adults born in Turkey and Morocco was included in LASA (wave MB). These migrants comprise the third and second largest groups of older nonWestern migrants living in the Netherlands [42]. In the 1960s and 1970s, predominantly male Turkish and Moroccan migrants arrived in the Netherlands to perform (mostly) physical manual labor [43]. Later waves of migration from these countries took place in the 1980s when many wives and children from Turkey and Morocco rejoined their husbands living in the Netherlands. It was expected that these groups would face a number of additional challenges in older age, relative to their Dutch age-peers. Many face language barriers [44], unemployment [45], poverty [46], discrimination and prejudice [47]. On average, they are expected to experience more rapid health decline than their native peers [48, 49], have higher levels of loneliness and depression [50], and are in greater need of care [46]. By including a sample of Turkish and Moroccan migrants living in the Netherlands we aimed to investigate functioning in the domains of social, physical, emotional and cognitive functioning in these groups and to compare their functioning to that of Dutch age-peers. In addition, we aimed to study how characteristics of migration contributed to functioning in these domains.

\section{Migrant cohort sample and measurements}

Data were collected among 478 older adults from Turkish $(n=269)$ and Moroccan $(n=209)$ origin with birth years between 1948 and 1957. The cooperation rate was $45 \%$. Because Turkish and Moroccan migrants in the Netherlands predominantly live in urban areas, data collection took place in 15 Dutch cities with population sizes between 85,000 and 805,000 inhabitants. Specifically, the cities were Amsterdam, Zwolle, Oss, Alkmaar, Almere, Amersfoort, Breda, Eindhoven, Enschede, Haarlem, Helmond, Hilversum, 
Table 7 Main measures in migrant cohort (wave MB, 2013-2014)

\begin{tabular}{|c|c|c|c|}
\hline Measure & Details & Main interview & $\begin{array}{l}\text { Medical } \\
\text { inter- } \\
\text { view }\end{array}$ \\
\hline \multicolumn{4}{|l|}{ Physical functioning } \\
\hline Body composition & Anthropometry & & $X$ \\
\hline Lifestyle factors & Self-report & & $X$ \\
\hline Chronic diseases & Self-report & $X$ & $\mathrm{X}$ \\
\hline Blood pressure & Blood pressure monitor & & $X$ \\
\hline Functional limitations & Self-report & $X$ & \\
\hline Physical performance & Performance test & $\mathrm{X}$ & \\
\hline Pain & Self-report & & $\mathrm{X}$ \\
\hline Falls/fractures & Self-report & & $X$ \\
\hline Medication & ATC codes & & $\mathrm{X}$ \\
\hline Self-rated health & Self-report & $\mathrm{X}$ & \\
\hline \multicolumn{4}{|l|}{ Cognitive functioning } \\
\hline General cognitive functioning & MMSE (illiterate and literate) & $X$ & \\
\hline Executive functioning & Verbal fluency & & $\mathrm{X}$ \\
\hline Memory; memory complaints & Self-report & $\mathrm{X}$ & \\
\hline \multicolumn{4}{|l|}{ Emotional functioning } \\
\hline Depressive symptoms & CES-D & & $X$ \\
\hline Personality trait & Mastery & & $\mathrm{X}$ \\
\hline \multicolumn{4}{|l|}{ Social functioning } \\
\hline Contact network & Contact frequency & $X$ & \\
\hline Loneliness & De Jong Gierveld loneliness scale & $X$ & \\
\hline Social participation & Self-report & $\mathrm{X}$ & \\
\hline \multicolumn{4}{|l|}{ Other } \\
\hline Demographic and socio-economic factors & Self-report & $X$ & \\
\hline Religion, Religiosity & Self-report, RCOPE & $\mathrm{X}$ & \\
\hline Use of care & Self-report & $\mathrm{X}$ & $\mathrm{X}$ \\
\hline \multicolumn{4}{|l|}{ Migrant specific } \\
\hline Family members' residence & Self-report & $X$ & \\
\hline Visits Turkey/Morocco & Self-report & $X$ & \\
\hline Participation in organizations & Self-report & $X$ & \\
\hline Acculturation & TECI & $X$ & \\
\hline Length of residence in the Netherlands & Self-report & $X$ & \\
\hline Ethnic identity & Self-report & $X$ & \\
\hline Care use in Turkey/Morocco & Self-report & $X$ & \\
\hline Considering return migration & Self-report & $X$ & \\
\hline
\end{tabular}

ATC Anatomical Therapeutic Chemical classification system, MMSE Mini Mental State Examination, $C E S-D$ Center for Epidemiologic Studies Depression scale, RCOPE Religious coping, TECI Taal en Cultuur Index [Language and Culture Index]
Nijmegen, Tilburg and Zaanstad. Trained interviewers of the same ethnic background conducted face-to-face interviews in Dutch, Turkish, Moroccan Arabic (Darija) or Berber language (Tarifit). If available, translated questionnaires were obtained from prior studies, such as the De Jong Gierveld Loneliness Scale [51] and the Center for Epidemiologic Studies Depression scale (CES-D) [52]. If questionnaires were not available in Moroccan Arabic, Berber or Turkish, questions were translated by two professional translators according to the back-and-forth method. All questionnaires were evaluated and tested in pilot-interviews.

Data were collected in a main interview and in a subsequent medical interview (Table 1). Of the respondents who participated in the main interview $(n=478)$, a large part was also interviewed in a medical interview $(n=344$, $72 \%$ ). The main measures are listed in Table 7 . No followup data have been collected among respondents included in the LASA migrant cohort. Data on mortality may 
become available in the near future, as vital status can be retrieved from municipality registers.

In the past few years, various studies using data from the LASA migrant cohort have been published. Two studies were conducted on transnational belonging [53,54]. One study found that those feeling marginalized were lonelier and that transnational belonging was not protective of loneliness [53]. The other study investigated determinants of transnational behavior and transnational belonging. Family-in-laws' location and gender explained transnational belonging, subjective income explained transnational behavior, and cultural distance and selfrated health explained both [54]. A study on wellbeing investigated whether private and public religious activities reduced the negative effects of a lack of physical, social and socio-economic resources on wellbeing. Private religious activities were positively associated with wellbeing but negatively associated with wellbeing in the context of lacking resources [55].

Three studies were performed in which the LASA migrant cohort was compared with native Dutch age-peers at wave 3B (2012-2013). First, a study on resilience in the disabling effect of physical impairments indicated that sense of mastery buffered against disability in those with physical impairment in the Turkish group. Income acted as a buffer against disability in those with physical impairment in the Dutch sample, but not in the migrant groups [56]. Second, measurement (in)variance of the CES-D was studied among older people of Dutch, Turkish and Moroccan origin, and the levels of depressive symptoms were compared. If the four sub-scales (i.e. depressed affect, positive affect, somatic symptoms and interpersonal problems) were used, scores were measurement invariant, which means that they measure the same construct across ethnic groups. However, migrants reported more depressive symptoms than native Dutch older adults on all sub-scales [57]. Finally, explanations for higher rates of loneliness among Turkish and Moroccan older adults compared to native Dutch older adults were examined. Less social participation, lower satisfaction with their income, poorer self-rated health and a higher number of depressive symptoms partially explained the higher rates of loneliness among migrants [58].

\section{Qualitative data collections}

The rich resource of quantitative data in the LASA database provides the possibility to purposively select and approach subsamples of older adults for in-depth, qualitative research. Capitalizing on this strength several ancillary qualitative data collections have taken place to answer specific research questions. For example, in-depth interviews about the meaning and experience of control in health care have been conducted [59]. In addition to providing new insights into the factors that may enhance older adults' sense of control, the conceptual model emerging from this qualitative study was subsequently used to develop a questionnaire measuring perceived control in health care [60]. Another qualitative study investigated resilience in older adults who aged successfully despite a low lifetime socioeconomic position (SEP) [61]. Previously calculated 16-year longitudinal trajectories of social, mental and physical functioning and three available indicators of SEP were used to identify the target group that was most likely to possess the experiences relevant to the research question. Furthermore, experiences of older Turkish and Moroccan migrants have been examined [62]. The life course experiences captured in the qualitative interviews provided insights into the aging experiences of migrants in the Netherlands, and the resources they use to cope with migration and aging related challenges. Finally, a photovoice study has been conducted among a purposively selected sample of LASA respondents living in the city of Amsterdam, who were asked to photograph aspects of their living environment that were important for their wellbeing. Photographs were then discussed in in-depth interviews to investigate the importance of the living environment for their wellbeing. This method enabled the researchers to capture a richer picture of the lived experiences and perceptions of older people. Besides, having participants decide for themselves what aspects they photographed gave them control over the contents and the direction of the interviews, which may empower participants [63].

These examples indicate that embedding qualitative ancillary studies in cohort studies such as LASA has several advantages. First, it enables researchers to answer questions on lay perceptions of aging and offers a 'thick description' of a topic of interest. Second, the results from qualitative studies can illustrate, complement and help to understand results from quantitative studies. For example, it may aid in developing new research ideas to be tested with quantitative methods, or in the development and implementation of new quantitative research instruments in the total LASA cohort.

One potential drawback of the ancillary qualitative studies is that they increase the burden on the participants, and this might negatively affect their subsequent participation in the ongoing study. However, our impression is that respondents welcome the variation in the mode of data collection. Additionally, the qualitative studies usually take place in a very small portion of the total sample $(\mathrm{n}<30)$, and are thus unlikely to substantially affect overall response rates.

Funding The Longitudinal Aging Study Amsterdam (LASA) is largely supported by a grant from the Netherlands Ministry of Health Welfare and Sports, Directorate of Long-Term Care. The data collection in 2012-2014 (wave 3B and wave MB) was financially supported by the Netherlands Organization for Scientific Research (NWO) in the 
framework of the project "New Cohorts of young old in the 21st century" (file number 480-10-014). The nine-monthly measurements among the 75 + were financially supported by the Netherlands Organization for Scientific Research (NWO) in the framework of the project "The Longitudinal Aging Study Amsterdam; a solid infrastructure for the social science of ageing in the oldest-old" (file number 481-11014). Genotyping for the first cohort using the Axiom-NL array was financially supported by a grant from EMGO + Research Institute. Emiel O. Hoogendijk was supported by an NWO/ZonMw Veni fellowship [grant number 91618067]. Martijn Huisman was supported by an NWO Vidi fellowship [grant number 480-11-017]. Funding was provided by Ministerie van Volksgezondheid, Welzijn en Sport.

Data availability LASA data are available for research. The LASA Steering Group has adopted a policy of sharing of data with interested researchers for specific research questions on aging-related issues. To obtain data, researchers need to submit an analysis proposal that is evaluated by the LASA Steering Group. Data are available for investigation under the condition that results of analyses will be made available to the research community through scientific reports or research papers, regardless of the results of the study. More information on data requests can be found on the LASA website: www.lasa-vu.nl. Forms to request assessment of biomarkers are also available here. We are open for collaborations in GWAS meta-analysis and gene-environment interaction studies. A specific analysis proposal format for GWAS meta-analysis is available on the website as well.

\section{Compliance with ethical standards}

Conflict of interest All the authors declare that they have no conflicts of interest.

Open Access This article is distributed under the terms of the Creative Commons Attribution 4.0 International License (http://creativeco mmons.org/licenses/by/4.0/), which permits unrestricted use, distribution, and reproduction in any medium, provided you give appropriate credit to the original author(s) and the source, provide a link to the Creative Commons license, and indicate if changes were made.

\section{References}

1. Huisman M, Poppelaars J, van der Horst M, Beekman AT, Brug J, van Tilburg TG, et al. Cohort profile: the Longitudinal Aging Study Amsterdam. Int J Epidemiol. 2011;40:868-76.

2. Hoogendijk EO, Deeg DJ, Poppelaars J, van der Horst M, Broese van Groenou MI, Comijs HC, et al. The Longitudinal Aging Study Amsterdam: cohort update 2016 and major findings. Eur J Epidemiol. 2016;31:927-45.

3. Ikram MA, Brusselle GGO, Murad SD, van Duijn CM, Franco OH, Goedegebure A, et al. The Rotterdam Study: 2018 update on objectives, design and main results. Eur J Epidemiol. 2017;32:807-50.

4. Smits CH, van den Beld HK, Aartsen MJ, Schroots JJ. Aging in the Netherlands: state of the art and science. Gerontologist. 2014;54:335-43.

5. Deeg DJH, Comijs HC, Hoogendijk EO, van der Noordt M, Huisman M. 23-year trends in life expectancy in good and poor physical and cognitive health at age 65 years in the Netherlands, 1993-2016. Am J Public Health. 2018;108:1652-8.

6. Timmermans EJ, Hoogendijk EO, Broese van Groenou MI, Comijs HC, van Schoor NM, Thomése GCF, et al. Trends across 20 years in multiple indicators of functioning among older adults in the Netherlands. Eur J Public Health. 2019. https://doi. org/10.1093/eurpub/ckz065.

7. Knipscheer CPM, De Jong Gierveld J, Van Tilburg TG, Dykstra PA. Living arrangements and social networks of older adults. Amsterdam: VU University Press; 1995.

8. Deeg DJ, van Tilburg T, Smit JH, de Leeuw ED. Attrition in the Longitudinal Aging Study Amsterdam. The effect of differential inclusion in side studies. J Clin Epidemiol. 2002;55:319-28.

9. Statistics Netherlands. Deaths; underlying cause of death (shortlist), sex, age. Retrieved February 7, 2019, http://statline.cbs.nl.

10. Wilson RS, Beck TL, Bienias JL, Bennett DA. Terminal cognitive decline: accelerated loss of cognition in the last years of life. Psychosom Med. 2007;69:131-7.

11. Ehli EA, Abdellaoui A, Fedko IO, Grieser C, Nohzadeh-Malakshah $\mathrm{S}$, Willemsen $\mathrm{G}$, et al. A method to customize populationspecific arrays for genome-wide association testing. Eur J Hum Genet. 2017;25:267-70.

12. Lam M, Awasthi S, Watson HJ, Goldstein J, Panagiotaropoulou G, Trubetskoy V, et al. RICOPILI: Rapid Imputation for COnsortias PIpeLIne. bioRxiv. 2019:587196.

13. Wray NR, Ripke S, Mattheisen M, Trzaskowski M, Byrne EM, Abdellaoui A, et al. Genome-wide association analyses identify 44 risk variants and refine the genetic architecture of major depression. Nat Genet. 2018;50:668-81.

14. Schizophrenia Working Group of the Psychiatric Genomics Consortium. Biological insights from 108 schizophrenia-associated genetic loci. Nature. 2014;511:421-7.

15. McCarthy S, Das S, Kretzschmar W, Delaneau O, Wood AR, Teumer A, et al. A reference panel of 64,976 haplotypes for genotype imputation. Nat Genet. 2016;48:1279-83.

16. Das S, Forer L, Schonherr S, Sidore C, Locke AE, Kwong A, et al. Next-generation genotype imputation service and methods. Nat Genet. 2016;48:1284-7.

17. Psaty BM, O'Donnell CJ, Gudnason V, Lunetta KL, Folsom AR, Rotter JI, et al. Cohorts for Heart and Aging Research in Genomic Epidemiology (CHARGE) Consortium: design of prospective meta-analyses of genome-wide association studies from 5 cohorts. Circ Cardiovasc Genet. 2009;2:73-80.

18. Tesi N, van der Lee SJ, Hulsman M, Jansen IE, Stringa N, van Schoor N, et al. Centenarian controls increase variant effect sizes by an average twofold in an extreme case-extreme control analysis of Alzheimer's disease. Eur J Hum Genet. 2019;27:244-53.

19. van der Lee SJ, Conway OJ, Jansen I, Carrasquillo MM, Kleineidam L, van den Akker E, et al. A nonsynonymous mutation in PLCG2 reduces the risk of Alzheimer's disease, dementia with Lewy bodies and frontotemporal dementia, and increases the likelihood of longevity. Acta Neuropathol. 2019. https://doi. org/10.1007/s00401-019-02026-8.

20. Marees AT, Hammerschlag AR, Bastarache L, de Kluiver H, Vorspan F, van den Brink W, et al. Exploring the role of lowfrequency and rare exonic variants in alcohol and tobacco use. Drug Alcohol Depend. 2018;188:94-101.

21. Smith B, Chu LK, Smith TC, Amoroso PJ, Boyko EJ, Hooper TI, et al. Challenges of self-reported medical conditions and electronic medical records among members of a large military cohort. BMC Med Res Methodol. 2008;8:37.

22. Kleipool EE, Hoogendijk EO, Trappenburg MC, Handoko ML, Huisman M, Peters MJ, et al. Frailty in older adults with cardiovascular disease: cause, effect or both? Aging Dis. 2018;9:489-97.

23. Pijpers E, Ferreira I, de Jongh RT, Deeg DJ, Lips P, Stehouwer $\mathrm{CD}$, et al. Older individuals with diabetes have an increased risk of recurrent falls: analysis of potential mediating factors: the Longitudinal Ageing Study Amsterdam. Age Ageing. 2012;41:358-65.

24. Verweij LM, van Schoor NM, Deeg DJ, Dekker J, Visser M. Physical activity and incident clinical knee osteoarthritis in older adults. Arthritis Rheum. 2009;61:152-7. 
25. Hoogendijk EO, Huisman M, van Ballegooijen AJ. The role of frailty in explaining the association between the metabolic syndrome and mortality in older adults. Exp Gerontol. 2017;91:5-8.

26. Executive Summary of The Third Report of The National Cholesterol Education Program (NCEP) Expert Panel on Detection, Evaluation, And Treatment of High Blood Cholesterol In Adults (Adult Treatment Panel III). JAMA. 2001;285:2486-97.

27. Van Ancum JM, Jonkman NH, van Schoor NM, Tressel E, Meskers CGM, Pijnappels M, et al. Predictors of metabolic syndrome in community-dwelling older adults. PLoS ONE. 2018;13:e0206424.

28. Seeman TE, McEwen BS, Rowe JW, Singer BH. Allostatic load as a marker of cumulative biological risk: MacArthur studies of successful aging. Proc Natl Acad Sci USA. 2001;98:4770-5.

29. Dent E, Kowal P, Hoogendijk EO. Frailty measurement in research and clinical practice: a review. Eur J Intern Med. 2016;31:3-10.

30. Hoogendijk EO, van Hout HP, Heymans MW, van der Horst HE, Frijters DH, Broese van Groenou MI, et al. Explaining the association between educational level and frailty in older adults: results from a 13-year longitudinal study in the Netherlands. Ann Epidemiol. 2014;24:538-44.

31. Hoogendijk EO, van Hout HP, van der Horst HE, Frijters DH, Dent E, Deeg DJ, et al. Do psychosocial resources modify the effects of frailty on functional decline and mortality? J Psychosom Res. 2014;77:547-51.

32. Hoogendijk EO, Theou O, Rockwood K, Onwuteaka-Philipsen BD, Deeg DJH, Huisman M. Development and validation of a frailty index in the Longitudinal Aging Study Amsterdam. Aging Clin Exp Res. 2017;29:927-33.

33. Hoogendijk EO, Rockwood K, Theou O, Armstrong JJ, Onwuteaka-Philipsen BD, Deeg DJH, et al. Tracking changes in frailty throughout later life: results from a 17-year longitudinal study in the Netherlands. Age Ageing. 2018;47:727-33.

34. van den Kommer TN, Deeg DJH, van der Flier WM, Comijs HC. Time trend in persistent cognitive decline: results from the Longitudinal Aging Study Amsterdam. J Gerontol B Psychol Sci Soc Sci. 2018;73(1):57-64.

35. Timmermans EJ, Lakerveld J, Beulens JWJ, Boomsma DI, Kramer SE, Oosterman M, et al. Cohort profile: the Geoscience and Health Cohort Consortium (GECCO) in the Netherlands. BMJ Open. 2018;8:e021597.

36. Beenackers MA, Doiron D, Fortier I, Noordzij JM, Reinhard E, Courtin E, et al. MINDMAP: establishing an integrated database infrastructure for research in ageing, mental well-being, and the urban environment. BMC Public Health. 2018;18:158.

37. Timmermans EJ, Schaap LA, Herbolsheimer F, Dennison EM, Maggi S, Pedersen NL, et al. The influence of weather conditions on joint pain in older people with osteoarthritis: results from the European Project on OSteoArthritis. J Rheumatol. 2015;42:1885-92.

38. Timmermans EJ, Schaap LA, Visser M, van der Ploeg HP, Wagtendonk AJ, van der Pas S, et al. The association of the neighbourhood built environment with objectively measured physical activity in older adults with and without lower limb osteoarthritis. BMC Public Health. 2016;15:710.

39. de Zwart F, Brunekreef B, Timmermans E, Deeg D, Gehring U. Air pollution and performance-based physical functioning in Dutch older adults. Environ Health Perspect. 2018;126:017009.

40. Generaal EH, Hoogendijk EO, Stam M, Henke CE, Rutters F, Oosterman M, et al. Neighbourhood characteristics and prevalence and severity of depression: pooled analysis of eight Dutch cohort studies. Br J Psychiatry. 2019;215:468-75.

41. NCD Risk Factor Collaboration (NCD-RisC). Rising rural bodymass index is the main driver of the global obesity epidemic in adults. Nature. 2019;569:260-4.
42. Statistics Netherlands. Prognosis population; sex, age, generation, migration background, periods. Retrieved March 31, 2019, http:// statline.cbs.nl.

43. Zorlu A, Hartog J. Migration and immigrants: the case of the Netherlands. Tinbergen Institute Discussion Paper. 2001.

44. Pot A, Keijzer M, De Bot K. The language barrier in migrant aging. Int J Biling Educ Biling. 2018. https://doi. org/10.1080/13670050.2018.1435627.

45. Snel E, Burgers J, Leerkes A. Class position of immigrant workers in a post-industrial economy: the Dutch case. J Ethnic Migr Stud. 2007;33:1323-42.

46. Reijneveld SA. Reported health, lifestyles, and use of health care of first generation immigrants in The Netherlands: do socioeconomic factors explain their adverse position? J Epidemiol Community Health. 1998;52:298-304.

47. Pettigrew TF, Jackson JS, Brika JB, Lemaine G, Meertens RW, Wagner U, et al. Outgroup prejudice in western Europe. Eur Rev Soc Psychol. 1997;8:241-73.

48. Reus-Pons M, Mulder CH, Kibele EUB, Janssen F. Differences in the health transition patterns of migrants and non-migrants aged 50 and older in southern and western Europe (2004-2015). BMC Med. 2018;16:57.

49. Ikram UZ, Kunst AE, Lamkaddem M, Stronks K. The disease burden across different ethnic groups in Amsterdam, the Netherlands, 2011-2030. Eur J Public Health. 2014;24:600-5.

50. Van der Wurff F, Beekman A, Dijkshoorn H, Spijker J, Smits C, Stek M, et al. Prevalence and risk-factors for depression in elderly Turkish and Moroccan migrants in the Netherlands. J Affect Disord. 2004;83:33-41.

51. Uysal-Bozkir Ö, Fokkema T, MacNeil-Vroomen JL, van Tilburg TG, de Rooij SE. Translation and validation of the De Jong Gierveld Loneliness Scale among older migrants living in the Netherlands. J Gerontol B Psychol Sci Soc Sci. 2017;72:109-19.

52. Spijker J, van der Wurff FB, Poort EC, Smits CH, Verhoeff AP, Beekman AT. Depression in first generation labour migrants in Western Europe: the utility of the Center for Epidemiologic Studies Depression Scale (CES-D). Int J Geriatr Psychiatry. 2004;19:538-44.

53. Klok J, van Tilburg TG, Suanet B, Fokkema T, Huisman M. National and transnational belonging among Turkish and Moroccan older migrants in the Netherlands: protective against loneliness? Eur J Ageing. 2017;14:341-51.

54. Klok J, van Tilburg TG, Suanet B, Fokkema T. Transnational aging among older Turkish and Moroccan migrants in the Netherlands: determinants of transnational behavior and transnational belonging. Transnatl Soc Rev. 2017;7:25-40.

55. Klokgieters SS, van Tilburg TG, Deeg DJH, Huisman M. Do religious activities among young-old immigrants act as a buffer against the effect of a lack of resources on well-being? Aging Ment Health. 2019;23:625-32.

56. Klokgieters SS, van Tilburg TG, Deeg DJH, Huisman M. Resilience in the disabling effect of gait speed among older Turkish and Moroccan immigrants and native Dutch. J Aging Health. 2018;30:711-37.

57. Klokgieters S, Mokkink L, Galenkamp H, Beekman A, Comijs H. Use of CES-D among 56-66 year old people of Dutch, Moroccan and Turkish origin: measurement invariance and mean differences between the groups. Curr Psychol. 2018. https://doi.org/10.1007/ s12144-018-9977-5.

58. van Tilburg TG, Fokkema T. Hogere eenzaamheid onder Marokkaanse en Turkse ouderen in Nederland: Op zoek naar een verklaring [Higher loneliness among Moroccan and Turkish older adults in the Netherlands: searching for an explanation]. Tijdschr Gerontol Geriatr. 2018;49:263-73.

59. Claassens L, Widdershoven GA, Van Rhijn SC, Van Nes F, Broese van Groenou MI, Deeg DJ, et al. Perceived control in health care: 
a conceptual model based on experiences of frail older adults. $\mathrm{J}$ Aging Stud. 2014;31:159-70.

60. Claassens L, Terwee CB, Deeg DJ, Broese van Groenou MI, Widdershoven GA, Huisman M. Development and validation of a questionnaire assessing the perceived control in health care among older adults with care needs in the Netherlands. Qual Life Res. 2016;25:859-70.

61. Kok AAL, van Nes F, Deeg DJH, Widdershoven G, Huisman M. "Tough times have become good times": resilience in older adults with a low socioeconomic position. Gerontologist. 2018;58:843-52.

62. Klokgieters SS, van Tilburg TG, Deeg DJH, Huisman M. The linkage between aging, migration and resilience: resilience in the life of older Turkish and Moroccan immigrants. J Gerontol B Psychol Sci Soc Sci. 2019. https://doi.org/10.1093/geronb/gbz024.

63. Mysyuk Y, Huisman M. Photovoice method with older persons: a review. Ageing Soc. 2018. https://doi.org/10.1017/s0144686x1 9000242.

Publisher's Note Springer Nature remains neutral with regard to jurisdictional claims in published maps and institutional affiliations. 